\title{
Intracranial and Extracranial Neurovascular Manifestations of Takayasu Arteritis
}

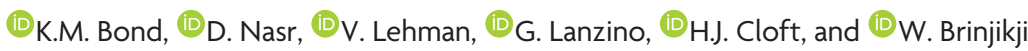

\begin{abstract}
BACKGROUND AND PURPOSE: Takayasu arteritis is a rare, large-vessel vasculitis that presents with symptoms related to end-organ ischemia. While the extracranial neurovascular manifestations of Takayasu arteritis are well-established, little is known regarding the intracranial manifestations. In this study, we characterize the intracranial and cervical neurovascular radiologic findings in patients with Takayasu arteritis.
\end{abstract}

MATERIALS AND METHODS: Patients with Takayasu arteritis who presented to our institution between 2001 and 2016 with intracranial and/or cervical vascular imaging were included in this study. Images were evaluated for the presence of vascular abnormalities, including intracranial or extracranial stenosis, vessel-wall thickening, dissection, subclavian steal, aneurysms, infarcts, and hemorrhages. Descriptive analyses are reported.

RESULTS: Seventy-nine patients with Takayasu arteritis met the criteria for inclusion in this study. The most common presenting neurologic symptoms were headache (32.9\%) and dizziness (15.2\%). Intracranial and extracranial vascular imaging was performed in $84.8 \%$ and $89.9 \%$ of patients, respectively. Among patients with intracranial vascular imaging, $3(3.9 \%)$ had intracranial aneurysms, $3(3.9 \%)$ had acute large-vessel occlusion, 6 (7.6\%) had intracranial vasculitis, and 1 (1.3\%) had reversible cerebrovascular constriction syndrome. Among patients with cervical vascular imaging, $42(53.1 \%)$ had some degree of narrowing of the common carotid artery and 18 (22.8\%) had narrowing of the ICAs. Seventeen patients $(23.6 \%)$ had subclavian steal.

CONCLUSIONS: Intracranial vascular abnormalities in patients with Takayasu arteritis presenting with neurologic symptoms are not rare, with cerebral vasculitis seen in $7.8 \%$ of patients, and stroke secondary to large-vessel occlusion, in $3.9 \%$ of patients. Cervical vascular manifestations of Takayasu arteritis were present in most patients in our study.

ABBREVIATION: TA = Takayasu arteritis

$\mathrm{T}$ akayasu arteritis (TA) is a chronic, large-vessel vasculitis of unknown etiology that typically affects young women. Granulomatous inflammation of the aorta and its main branches gradually leads to stenosis and symptomatology related to end-organ ischemia. ${ }^{1,2}$ The clinical presentation of patients with TA varies greatly and depends on the degree and location of disease progression. Cerebral ischemia can give rise to neurologic symptoms such as headache, seizure, stroke, syncope, and visual disturbances. ${ }^{3-6}$ These neurologic manifestations have been estimated to affect

Received September 21, 2016; accepted December 6.

From the Mayo Clinic School of Medicine (K.M.B.), Rochester, Minnesota; and Departments of Neurology (D.N.), Radiology (V.L., G.L., H.J.C., W.B.), and Neurosurgery (G.L.), Mayo Clinic, Rochester, Minnesota.

Please address correspondence to Waleed Brinjikji, MD, Mayo Clinic, Department of Radiology, 200 1st St SW, Rochester, MN 55905; e-mail: brinjikji.waleed@mayo.edu; @WBrinjikji

三 Indicates article with supplemental on-line table.

http://dx.doi.org/10.3174/ajnr.A5095 between $42 \%$ and $80 \%$ of patients with TA and are usually secondary to large-vessel involvement of the disease. ${ }^{1,5}$

A number of studies have also reported that intracranial involvement, including steno-occlusive disease and aneurysms, is rare in patients with TA. ${ }^{1,6-10}$ Studies providing a comprehensive description of the characteristics and prevalence of the spectrum of neurovascular involvement of TA (ie, intracranial and extracranial) are scarce. In this study, we examined the characteristics and prevalence of neurovascular imaging abnormalities (both intra- and extracranial) among patients with a clinical diagnosis of TA with an emphasis on intracranial vascular manifestations.

\section{MATERIALS AND METHODS Patient Population}

Following institutional review board approval, we retrospectively reviewed the medical records of patients with a clinical diagnosis of TA. Patients were identified by querying our medical records for the term "Takayasu arteritis" and identifying those billed with 
Table 1: Demographics and presenting symptoms of patients with Takayasu arteritis

\begin{tabular}{lc}
\hline \multicolumn{1}{c}{ Demographics } & No. $(\%)$ \\
\hline No. of patients & $79(100)$ \\
Mean age (SD) (yr) & $33.2(10.3)$ \\
Mean (SD) follow-up (mo) & $74.4(59.9)$ \\
Sex & \\
Male & $7(8.9)$ \\
Female & $72(91.1)$ \\
Race & \\
White & $60(75.9)$ \\
Asian & $6(7.6)$ \\
Black & $3(3.8)$ \\
American Indian & $3(3.8)$ \\
Hispanic & $1(1.3)$ \\
Other & $3(3.8)$ \\
Unknown & $3(3.8)$ \\
Imaging studies & \\
Intracranial imaging & $67(84.8)$ \\
CTA & $25(31.6)$ \\
DSA & $9(11.4)$ \\
MRA & $55(69.6)$ \\
MRI & $43(54.5)$ \\
Cervical imaging & $71(89.9)$ \\
CTA & $33(41.8)$ \\
DSA & $1(1.3)$ \\
MRA & $55(69.6)$ \\
Symptomatology & \\
Neurologic symptoms & \\
Dizziness & \\
Headache & $12(15.2)$ \\
Hemiplegia/hemisensory loss & $26(32.9)$ \\
Syncope & $5(6.3)$ \\
Vision loss & $5(6.3)$ \\
Limb claudication & $10(12.7)$ \\
Other symptoms & $32(40.5)$ \\
Clinical diagnosis of stroke & $13(16.5)$ \\
Acute ischemia & \\
Transient ischemic attack & $9(11.4)$ \\
Intracranial hemorrhage & $5(6.3)$ \\
\hline & $1(1.3)$ \\
\hline
\end{tabular}

the International Classification of Diseases-9 code for TA (446.7) (http://www.icd9cm.chrisendres.com/). All records were reviewed for evidence of a definite diagnosis of TA per previously defined criteria. ${ }^{11}$ Only patients who underwent cervical and/or intracranial imaging (angiography, CTA, MRA, and/or MR imaging) between January 2001 and April 2016 were included in this study.

\section{Demographics and Clinical Presentation}

The following baseline information was extracted from each patient's record: age at the time of imaging, sex, race, and duration of follow-up. Clinical notes were reviewed for evidence of neurologic symptoms, including dizziness, headache, hemiplegia or hemisensory loss, syncope, and vision loss. Charts were also reviewed for a clinical diagnosis of stroke, transient ischemic attack, or symptomatic intracranial hemorrhage.

\section{Imaging Evaluation}

All imaging reports and studies were evaluated by a single radiologist. Cervical vascular imaging was evaluated for abnormalities of the carotid and vertebral arteries, including stenosis, vessel thickening (carotid vessels only), dissection, and vertebral artery
Table 2: Extracranial vascular imaging findings

\begin{tabular}{|c|c|}
\hline Finding & No. (\%) \\
\hline Cervical dissection & $1(1.3)$ \\
\hline Retrograde VA flow & $17(23.6)$ \\
\hline Vessel thickening & $33(62.3)$ \\
\hline L CCA & $31(58.5)$ \\
\hline R CCA & $29(54.7)$ \\
\hline LICA & $8(15.1)$ \\
\hline RICA & 8 (15.1) \\
\hline Stenosis & $47(59.5)$ \\
\hline \multicolumn{2}{|l|}{ Degree of stenosis } \\
\hline \multicolumn{2}{|l|}{ Any CCA } \\
\hline Mild & $16(20.3)$ \\
\hline Moderate/severe & $17(21.6)$ \\
\hline Occluded & 15 (19.0) \\
\hline \multicolumn{2}{|l|}{ LCCA } \\
\hline Mild & $11(13.9)$ \\
\hline Moderate/severe & 14 (17.8) \\
\hline Occluded & 11 (13.9) \\
\hline \multicolumn{2}{|l|}{$\mathrm{RCCA}$} \\
\hline Mild & 12 (15.2) \\
\hline Moderate/severe & $6(7.6)$ \\
\hline Occluded & 9 (11.4) \\
\hline \multicolumn{2}{|l|}{ Any ICA } \\
\hline Mild & $6(7.6)$ \\
\hline Moderate/severe & $4(5.1)$ \\
\hline Occluded & 8 (10.1) \\
\hline \multicolumn{2}{|l|}{ LICA } \\
\hline Mild & $4(5.1)$ \\
\hline Moderate/severe & $2(2.5)$ \\
\hline Occluded & $2(2.5)$ \\
\hline \multicolumn{2}{|l|}{ RICA } \\
\hline Mild & $4(5.1)$ \\
\hline Moderate/severe & $2(2.5)$ \\
\hline Occluded & $7(8.9)$ \\
\hline \multicolumn{2}{|l|}{ Any VA } \\
\hline Mild & $5(6.3)$ \\
\hline Moderate/severe & $4(5.1)$ \\
\hline Occluded & $6(7.6)$ \\
\hline \multicolumn{2}{|l|}{ L VA } \\
\hline Mild & $3(3.8)$ \\
\hline Moderate/severe & $3(3.8)$ \\
\hline Occluded & $3(3.8)$ \\
\hline \multicolumn{2}{|l|}{ R VA } \\
\hline Mild & $3(3.8)$ \\
\hline Moderate/severe & $3(3.8)$ \\
\hline Occluded & $4(5.1)$ \\
\hline
\end{tabular}

Note:- L indicates left; R, right; CCA, common carotid artery; VA, vertebral artery.

retrograde flow indicative of subclavian steal. The degree of stenosis was measured as none, mild $(<50 \%)$, moderate $(50 \%-$ $70 \%)$, severe $(>70 \%)$, or occluded per the NASCET criteria. Cervical vascular thickening was only documented if the patient had a CTA or sonogram. Vessel-wall thickening was defined as an intimal-medial thickness of $\geq 2 \mathrm{~mm}$. No vessel-wall imaging was performed on MR imaging in any of the patients.

Intracranial vascular imaging (including CTA, DSA and MRA) was evaluated for the presence of aneurysms, stenosis, occlusions, and arteriovenous shunting. Intracranial stenoses and occlusions were further classified on the basis of etiology (ie, vasculitis, embolic large-vessel occlusion, reversible cerebral vasoconstriction syndrome, dissection, and so forth). Intracranial distribution of disease was determined as well. Brain MRIs were also evaluated for evidence of acute and chronic infarcts, microhemorrhage, and white matter disease. 


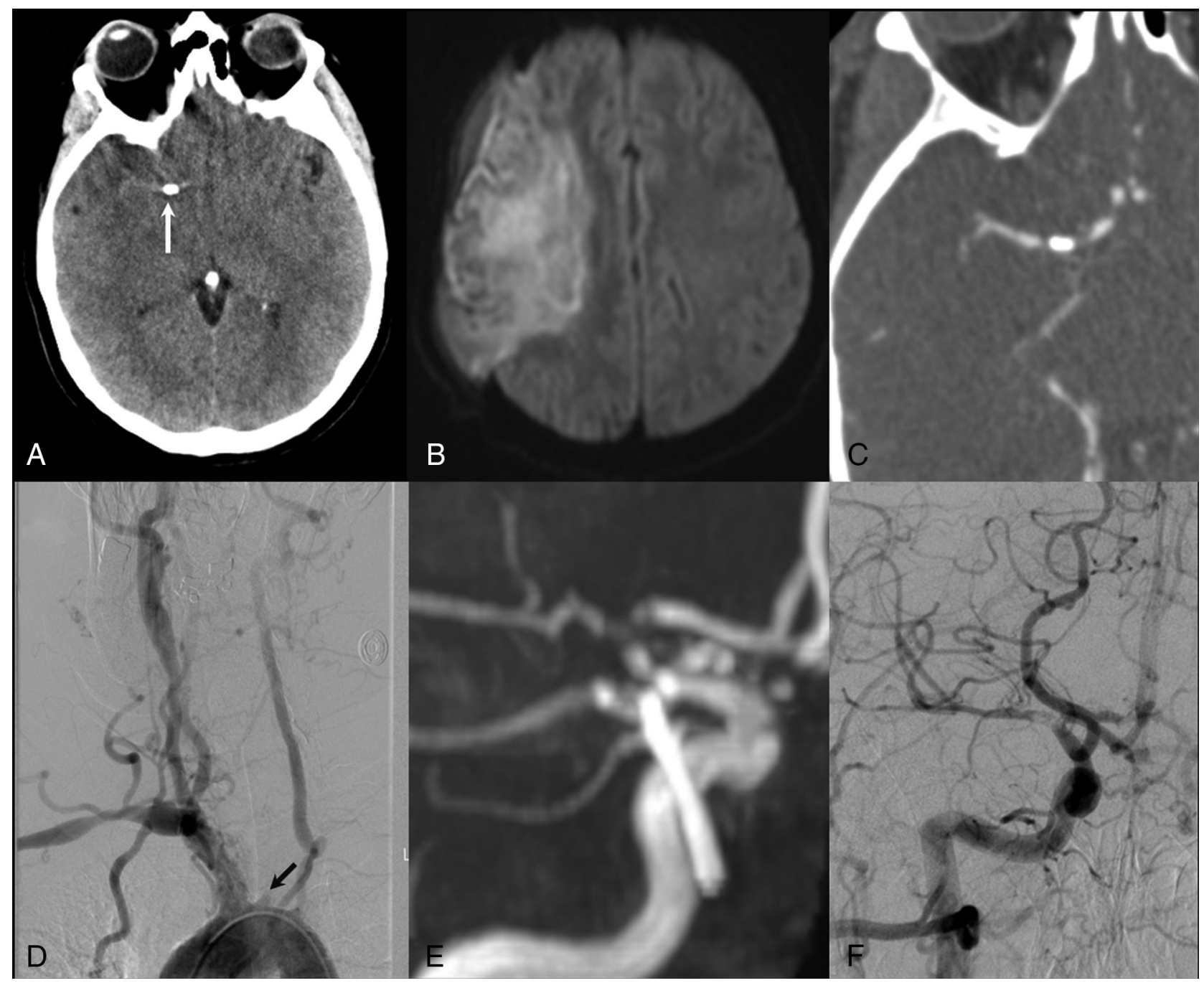

FIG 1. A 36-year-old woman who presented with acute-onset left-sided hemiparesis. A, Noncontrast CT demonstrates a calcified embolus (white arrow) in the right ICA terminus along with loss of gray-white differentiation of the right basal ganglia. $B$, Diffusion-weighted MR imaging demonstrates a large right hemispheric infarct. C, CTA confirms a calcified embolus at the ICA termination. D, An arch aortogram demonstrates occlusion of the left common carotid artery origin (black arrow) along with multifocal narrowing of the right subclavian artery and right common carotid artery. There is occlusion of the left subclavian artery distal to its origin. E, MRA performed 12 months following the initial presentation shows chronic near-occlusion of the ICA terminus. F, Right common carotid artery cerebral angiogram shows a filling defect at the MCA origin, consistent with the now-chronic calcified embolus.

\section{Statistical Analysis}

No statistical comparisons were made in this study. Categoric outcomes were reported as number (percentage), and continuous outcomes were reported as mean $\pm \mathrm{SD}$. Statistical analyses were performed by using JMP 12.0 (SAS Institute, Cary, North Carolina).

\section{RESULTS}

\section{Patient Demographics}

Seventy-nine patients at our institution were clinically diagnosed with TA and had intracranial and/or cervical vascular imaging. Seventy-two $(91.1 \%)$ patients were women, with a mean age of $33.2 \pm 10.3$ years. Most patients were white (75.9\%). Sixty-seven $(84.8 \%)$ patients had intracranial vascular imaging, and 71 (89.9\%) had cervical vascular imaging. Forty-three (54.5\%) patients had a head MR imaging. Patient demographics are summarized in Table 1.

\section{Clinical Presentation}

The most common neurologic symptom was headache (32.9\%). Twelve patients (15.2\%) had dizziness, 10 (12.7\%) had vision loss, 5 had hemiplegia or hemisensory loss following stroke, and 5 (6.3\%) had syncope. Thirty-two patients (40.5\%) presented with symptoms of limb claudication, including paresthesia, sensory loss, weakness, and pain on exertion. Thirteen (16.5\%) patients presented without neurologic symptoms or limb claudication. In total, $9(11.4 \%)$ patients presented with acute ischemic stroke; 5 (6.3\%), with TIA; and 1 (1.3\%), with symptomatic intracranial hemorrhage. These data are summarized in Table 1.

\section{Intracranial Vascular Findings}

Intracranial vascular imaging findings are summarized in the Online Table. As mentioned previously, 67 patients had intracranial vascular imaging (ie, MRA, CTA, or DSA). Of these patients, 9 (13.4\%) had evidence of intracranial arterial stenosis or occlusion 


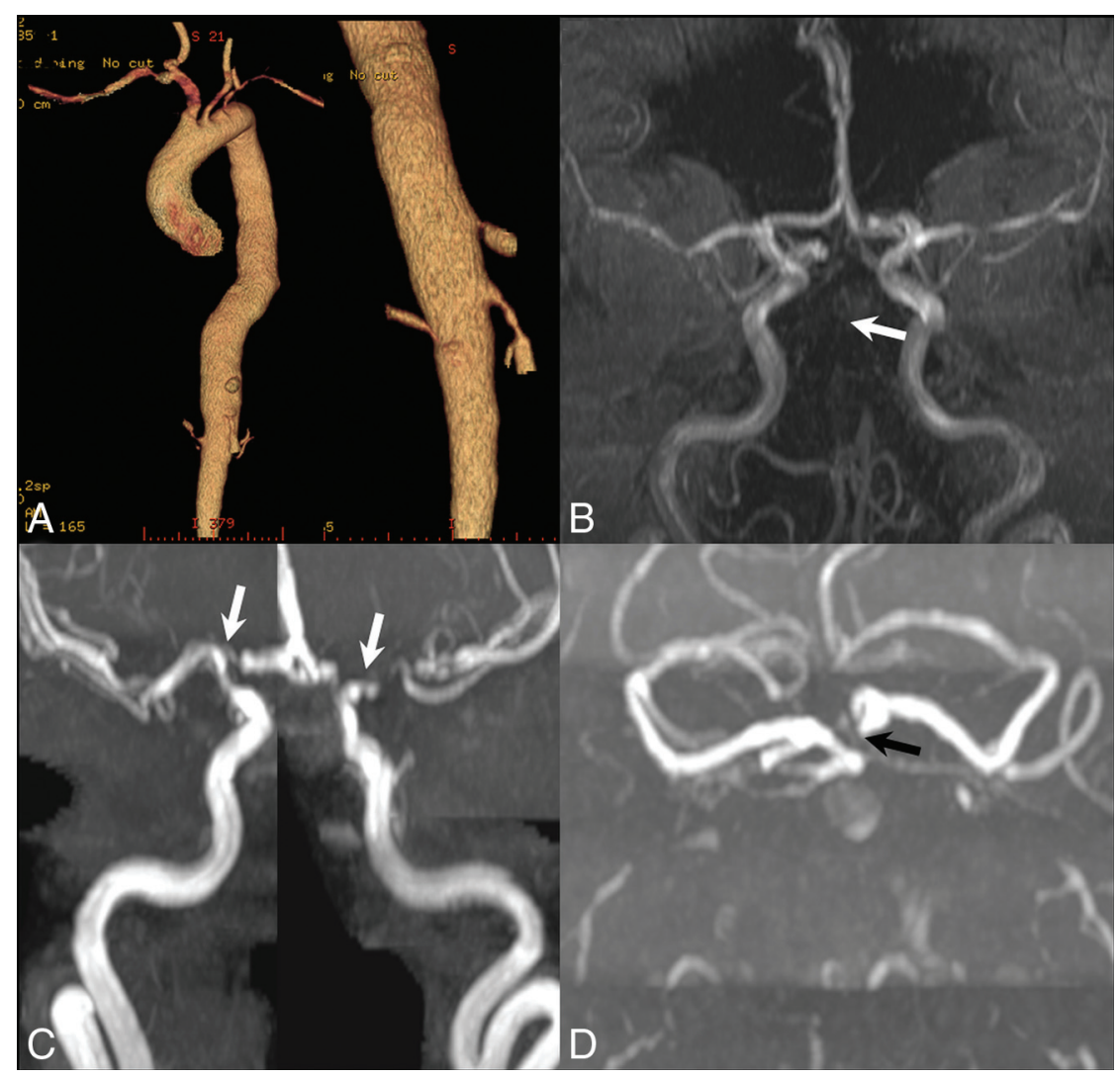

FIG 2. A 49-year-old woman with sudden-onset left sensorineural hearing loss. A, CTA of the thoracic aorta and abdominal aorta demonstrates stenosis of the bilateral subclavian arteries, descending thoracic aorta, celiac and superior mesenteric artery origins, and the bilateral renal arteries. $B$, MRA at the time of presentation with sensorineural hearing loss shows an occluded basilar artery (white arrow) with no stenosis of the supraclinoid ICAs. MRA 1 year later shows high-grade stenosis of the bilateral ICA termini (C, white arrows) and persistent occlusion of the basilar artery $(D)$, with new stenosis (black arrow) of the left posterior cerebral artery. She had no intervening stroke during this time.

and 3 patients $(4.5 \%)$ had an intracranial aneurysm. Among patients with intracranial arterial stenosis or occlusion, 8 were female and 1 was male. The mean age of patients with intracranial vascular narrowing or occlusion was $34.9 \pm 12.0$ years. Two patients had an acute large-vessel occlusion secondary to calcified emboli, which eventually developed into chronic MCA occlusions. Five patients had multifocal intracranial vascular narrowing compatible with intracranial vasculitis. One patient had a focal narrowing in the left MCA from a prior embolic large-vessel occlusion and multifocal areas of the intracranial vasculature compatible with vasculitis. One patient presented with severe headache and had diffuse narrowing of the proximal and distal intracranial vasculature, which reversed after 3 months, consistent with reversible cerebral vasoconstriction syndrome. Thus, in total, 3 patients had intracranial vascular narrowing from largevessel occlusion, 6 patients had intracranial vascular narrowing from vasculitis involving small and medium-sized intracranial vessels, and 1 patient had intracranial vascular narrowing from reversible cerebral vasoconstriction syndrome. In total, 6 of the 9 patients with intracranial vascular involvement had imaging evidence of an ischemic stroke. All patients with small- and mediumsized intracranial vessel involvement also had aortic arch involvement of TA. Figures 1-3 demonstrate representative cases of steno-occlusive disease. One of the patients with intracranial aneurysm had subarachnoid hemorrhage (Fig 4).

\section{Intracranial MR Imaging Findings}

In total, 19 patients $(26.3 \%)$ had imaging evidence of either an acute or chronic infarct. Acute infarcts were seen in 9 patients (12.5\%), and chronic infarcts were seen in 17 patients $(23.6 \%)$. Microhemorrhage, as seen on $\mathrm{T} 2{ }^{*}$-weighted imaging, was present in $4(6.2 \%)$ patients. T2 hyperintense white matter lesions consistent with small-vessel ischemic disease were present in 25 (34.7\%) patients.

\section{Cervical Imaging Findings}

The most common cervical vascular finding among patients with TA was common carotid artery narrowing. Forty-eight patients $(60.8 \%)$ had any degree of narrowing of a common carotid artery. The left common carotid artery was more commonly affected than the right (36 cases, $45.6 \%$, versus 27 cases, $34.2 \%$, respectively). In total, 18 (22.8\%) had narrowing of the internal carotid artery. The right internal carotid artery was affected more often than the left ( 13 cases, $16.5 \%$, versus 8 cases, $10.1 \%$, respectively). The proportion of patients with any vertebral artery stenosis was $19 \%$ (15 patients). Nine (11.4\%) left vertebral arteries and 10 $(12.7 \%)$ right vertebral arteries were affected. All patients with internal carotid artery involvement also had common carotid artery involvement. The involvement of the ICA was continuous with the common carotid artery involvement in all cases. Among patients with MRAs and/or sonograms, retrograde vertebral ar-

AJNR Am J Neuroradiol 38:766-72 Apr 2017 www.ajnr.org 


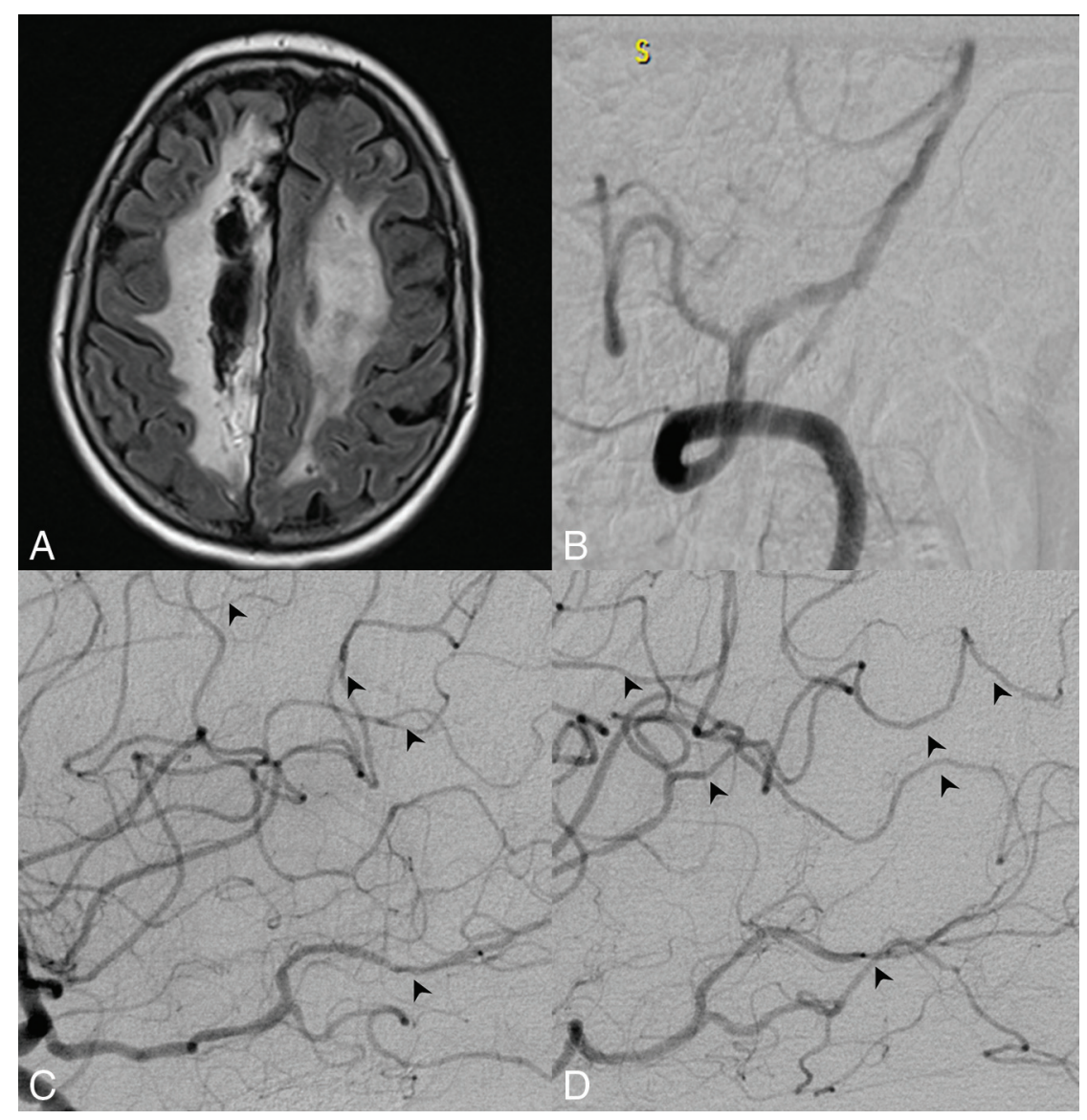

FIG 3. A 52-year-old woman who presented with subacute left-sided weakness. A, T2/FLAIR MR imaging demonstrates confluent areas of high T2 signal throughout the subcortical periventricular white matter of both hemispheres, consistent with chronic ischemic changes with encephalomalacia on the right. There were also chronic infarcts in the bilateral thalami and left pons (not shown). B, Left vertebral artery cerebral angiogram demonstrates diffuse mild irregularity of the basilar artery. Left ICA $(C)$ and right ICA $(D)$ cerebral angiograms in the lateral projection demonstrate multifocal areas of luminal narrowing in the distal territories of the anterior cerebral arteries, MCAs, and posterior cerebral arteries bilaterally, consistent with vasculitis.

tery flow secondary to proximal subclavian stenosis or occlusion was present in $17(23.6 \%)$. One (1.3\%) patient had a cervical dissection. These findings are summarized in Table 2.

\section{DISCUSSION}

While it is known that intracranial manifestations of TA are rare, we found that $>10 \%$ of patients had some form of intracranial stenosis, most commonly in a vasculitic pattern. Chronic intracranial large-vessel occlusion secondary to emboli was present in approximately $5 \%$ of patients. Most patients had at least mild cervical vascular disease that most commonly affected the common carotid arteries. Cervical internal carotid artery involvement was rare. Evidence of cerebral infarction was found in nearly $25 \%$ of patients. These findings are important because they both highlight that intracranial vascular involvement of TA is not as rare as previously thought, and they demonstrate that the rate of stroke secondary to neurovascular manifestations of TA is quite high.

While several studies have detailed the prevalence and characteristics of large-vessel involvement of TA, intracranial arterial disease has only been described in studies with a few patients or without advanced vascular imaging. ${ }^{6,7,10,12-15}$ In a series of 7 patients who underwent cerebral DSA for evaluation of neurologic symptoms related to TA, Cantú et $\mathrm{al}^{7}$ found that no patients had intracranial stenosis, vasculitis, or occlusion secondary to TA. In another study of 7 patients with TA presenting with TIA, Takano et $\mathrm{al}^{14}$ found that 3 had an intracranial stenosis but they did not characterize the lesions. In a study of 142 patients undergoing transcranial Doppler sonography, Hoffmann et al ${ }^{8}$ found elevated velocities suggestive of stenosis in the anterior circulation in just 7 patients. However, no patients in this study had confirmatory arteriographic imaging detailing the anatomic distribution of disease. Last, in a study of 17 patients with TA with cerebrovascular imaging, Ringleb et $\mathrm{al}^{6}$ found intracranial stenoses in 7 patients, but again, this study failed to characterize the etiology of these lesions. Our study, the largest to date with cerebral arteriographic imaging in patients with TA, to our knowledge, found intracranial arterial involvement of TA in $15.2 \%$ of patients, with $7.6 \%$ of patients having CNS vasculitis.

Intracranial stenoses in TA could be secondary to inflammatory vasculitis or the result of prior embolization. In our series, 6 patients had multifocal stenoses in a vasculitic pattern, which were compatible with an inflammatory vasculitis etiology. Intracranial vasculitis from TA has been reported in prior studies and has been proved pathologically in at least 1 case. ${ }^{10}$ Most interest- 


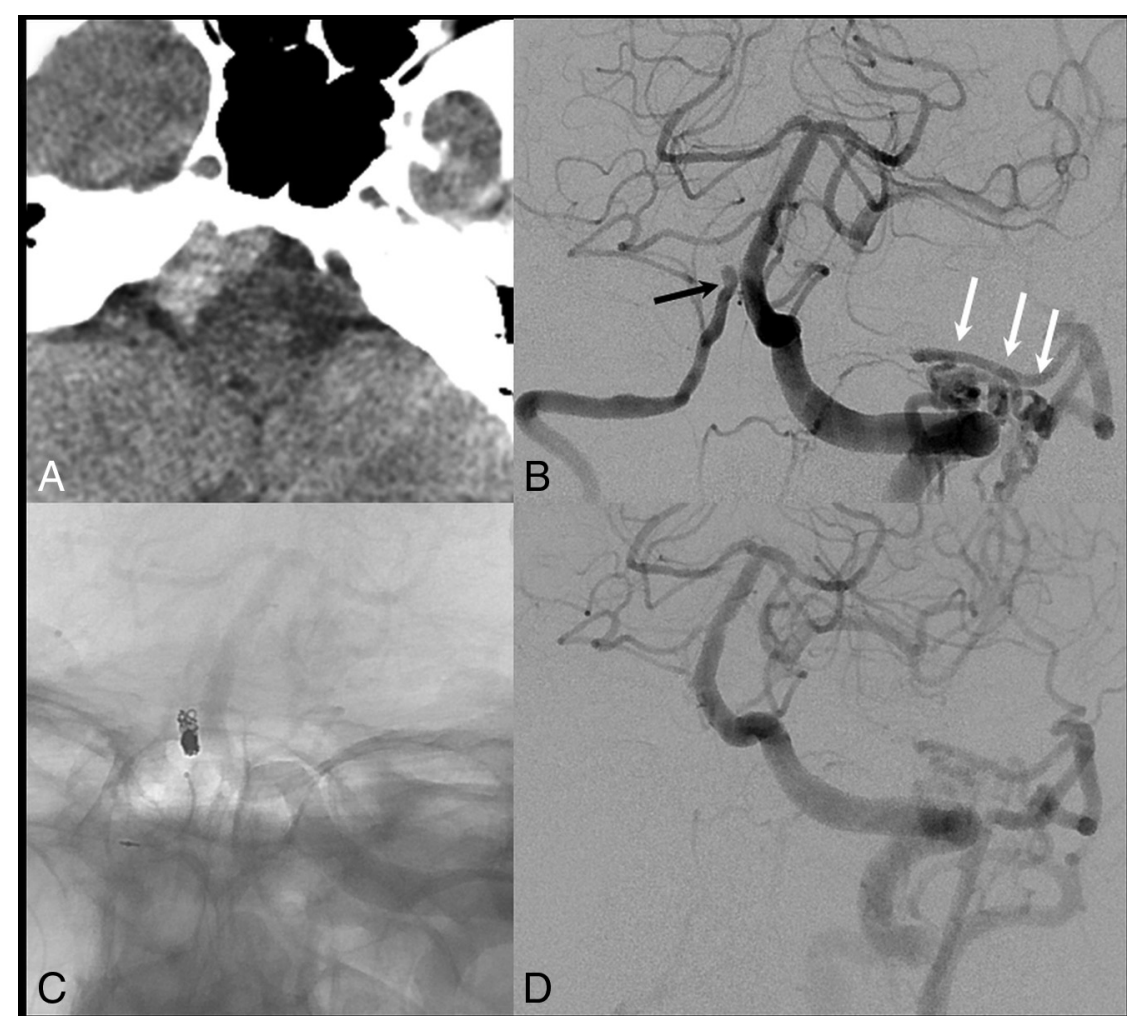

FIG 4. A 66-year-old woman with a nearly 20-year diagnosis of Takayasu arteritis with pan-aortic disease, bilateral common carotid artery involvement, and bilateral subclavian disease. $A$, The patient presented with acute headache and visual symptoms, and noncontrast CT demonstrates attenuated subarachnoid hemorrhage isolated to the right side of the prepontine and premedullary cisterns. $B$, Left vertebral artery cerebral angiogram demonstrates a focal outpouching of the distal intradural right vertebral artery (black arrow), with a focal stenosis just distal to the aneurysm. There was no PICA origin at this location because the PICA arose from a right AICA-PICA trunk. Also, note the prominent collaterals between the left vertebral artery and occipital artery secondary to long-term occlusion of the left external carotid artery in Takayasu arteritis (white arrows). C, The distal right vertebral artery was occluded with coils. D, Repeat left vertebral artery cerebral angiogram demonstrates occlusion of the intradural right vertebral artery.

ing, cases of intracranial vasculitis demonstrate a pattern of inflammation similar to that of the aorta and major cervical arteries in TA. One patient with intracranial vasculitis in our series also had idiopathic carotid terminus occlusions, which had a similar appearance to Moyamoya disease. This has also been reported in prior case reports, ${ }^{16,17}$ and the exact prevalence of this finding and the pathophysiology in patients with TA are still unknown. Unlike those with typical Moyamoya disease, however, this patient initially presented with a basilar artery occlusion (Fig 2). One patient in our series had reversible cerebral vasoconstriction syndrome, which, in the setting of TA, has only been described in 1 prior case report. ${ }^{18}$ Intracranial stenosis can also result from artery-to-artery emboli, resulting in large-vessel occlusion as seen in 3 patients in our study. Intracranial involvement of TA was never an isolated finding because all patients with intracranial vascular involvement of TA also had extracranial manifestations, including the aorta and/or major aortic branch vessels.

Extracranial vascular abnormalities are the most common cause of ischemic neurologic symptoms in TA. ${ }^{19,20}$ The rate of common carotid artery stenosis has been reported to be $21 \%-$ $65 \%$, compared with $16 \%-18 \%$ in the internal carotid arteries and $12 \%-33 \%$ in the vertebral arteries. ${ }^{6,7,21}$ As opposed to stenotic disease secondary to atherosclerosis, these studies have identified concentric vessel-wall thickening as opposed to eccentric wall thickening as the cause of the stenosis. ${ }^{6,9,22}$ In agreement with our data, prior studies have found that involvement of the internal carotid arteries, vertebral arteries, and intracranial vasculature is substantially less common than of the common carotid and subclavian arteries. ${ }^{6,9,22}$

\section{Limitations}

Our study has limitations. First, its retrospective design limits the uniformity of diagnostic criteria and imaging protocols. Many patients were excluded from this study due to a lack of cervical and intracranial imaging. As a result of this selection bias, our cohort likely has a higher prevalence of neurologic symptoms and cerebrovascular abnormalities than the general TA population. Patients underwent different types of arteriographic imaging studies, each with their own sensitivities and limitations. Imaging of vessel walls was not performed in any patient. Another variable that limits the generalizability of our findings is that most patients included in this study were white, in whom supra-aortic blood vessel involvement is more common. ${ }^{6}$ It is known that the anatomic distribution of TA progression is influenced by ethnicity. ${ }^{1,23}$ Thus, it is important to consider the racial/ethnic composition of our cohort when interpreting our results.

\section{CONCLUSIONS}

In our study of 79 patients with Takayasu arteritis, neurovascular manifestations were relatively common. The common carotid ar- 
teries were affected most often, followed by the internal carotid arteries and the intracranial vasculature. Intracranial manifestations of Takayasu arteritis can closely resemble those of primary CNS vasculitis. Further studies are needed to better define the prevalence and risk factors of intracranial manifestations of TA and to identify the best treatments.

Disclosures: Giuseppe Lanzino_-UNRELATED: Consultancy: Covidien/Medtronic.* *Money paid to the institution.

\section{REFERENCES}

1. Kerr GS, Hallahan CW, Giordano J et al. Takayasu arteritis. Ann Intern Med 1994;120:919-29 CrossRef Medline

2. Subramanyan R, Joy J, Balakrishnan KG. Natural history of aortoarteritis (Takayasu's disease). Circulation 1989;80:429-37 CrossRef Medline

3. Bolaman Z, Yavasoglu I, Kadikoylu G, et al. Takayasu arteritis with intracranial involvement mimicking epilepsy: case report and review of the literature. Intern Med 2011;50:1345-48 CrossRef Medline

4. Duarte MM, Geraldes R, Sousa R, et al. Stroke and transient ischemic attack in Takayasu's arteritis: a systematic review and metaanalysis. J Stroke Cerebrovasc Dis 2016;25:781-91 CrossRef Medline

5. Kim HJ, Suh DC, Kim JK, et al. Correlation of neurological manifestations of Takayasu's arteritis with cerebral angiographic findings. Clin Imaging 2005;29:79-85 CrossRef Medline

6. Ringleb PA, Strittmatter EI, Loewer M, et al. Cerebrovascular manifestations of Takayasu arteritis in Europe. Rheumatology (Oxford) 2005;44:1012-15 CrossRef Medline

7. Cantú C, Pineda C, Barinagarrementeria F, et al. Noninvasive cerebrovascular assessment of Takayasu arteritis. Stroke 2000;31:2197202 CrossRef Medline

8. Hoffmann M, Corr P, Robbs J. Cerebrovascular findings in Takayasu disease. J Neuroimaging 2000;10:84-90 CrossRef Medline

9. Kissin EY, Merkel PA. Diagnostic imaging in Takayasu arteritis. Curr Opin Rheumatol 2004;16:31-37 CrossRef Medline

10. Molnár P, Hegedüs K. Direct involvement of intracerebral arteries in Takayasu's arteritis. Acta Neuropathol 1984;63:83-86 CrossRef Medline

11. de Souza AW, de Carvalho JF. Diagnostic and classification criteria of Takayasu arteritis. J Autoimmun 2014;48-49:79-83 CrossRef Medline

12. Call GK, Fleming MC, Sealfon S, et al. Reversible cerebral segmental vasoconstriction. Stroke 1988;19:1159-70 CrossRef Medline

13. Sikaroodi H, Motamedi M, Kahnooji H, et al. Stroke as the first manifestation of Takayasu arteritis. Acta Neurol Belg 2007;107: 18-21 Medline

14. Takano K, Sadoshima S, Ibayashi S, et al. Altered cerebral hemodynamics and metabolism in Takayasu's arteritis with neurological deficits. Stroke 1993;24:1501-06 CrossRef Medline

15. Klos K, Flemming KD, Petty GW, et al. Takayasu's arteritis with arteriographic evidence of intracranial vessel involvement. Neurology 2003;60:1550-51 CrossRef Medline

16. Skeik N, Rumery KK, Udayakumar PD, et al. Concurrent Takayasu arteritis with common variable immunodeficiency and moyamoya disease. Ann Vasc Surg 2013;27:240.e13-18 CrossRef Medline

17. Zhang RY, Wang QY, Liu HW, et al. A case report of general Takayasu syndrome complicated by Moyamoya disease [in Chinese]. Zhongguo Dang Dai Er Ke Za Zhi 2011;13:524-26 Medline

18. Uchida Y, Matsukawa N, Oguri T, et al. Reversible cerebral vasoconstriction syndrome in a patient with Takayasu's arteritis. Intern Med 2011;50:1611-14 CrossRef Medline

19. Vanoli M, Daina E, Salvarani C, et al. Takayasu's arteritis: a study of 104 Italian patients. Arthritis Rheum 2005;53:100-07 CrossRef Medline

20. Wang Z, Shen L, Yu J, et al. Management of cerebral ischemia due to Takayasu's arteritis. Chinese Med J (Engl) 2002;115:342-46 Medline

21. Park BW, Park SJ, Park H, et al. Stenosis or occlusion of the right subclavian and common carotid arteries is more common than that of the innominate artery in Takayasu arteritis. Vasc Specialist Int 2015;31:120-24 CrossRef Medline

22. Schmidt WA, Nerenheim A, Seipelt E, et al. Diagnosis of early Takayasu arteritis with sonography. Rheumatology 2002;41:496-502 CrossRef Medline

23. Moriwaki R, Noda M, Yajima M, et al. Clinical manifestations of Takayasu's arteritis in India and Japan: new classification of angiographic findings. Angiology 1997;57:27-35 Medline 